\title{
Permanence of a long temporal gradient of retrograde amnesia induced by electroconvulsive shock $^{1}$
}

\begin{abstract}
ANNE GELLER and M. E. JARVIK, Albert Einstein College of Medicine, Bronx, N.Y. 10461, and FRANCESCO ROBUSTELLI, Istituto di Psicologia del Consiglio Nazionale delle Ricerche, Rome, Italy
\end{abstract}

Electroconvulsive shock (ECS) was administered to mice $10 \mathrm{sec}, 120 \mathrm{sec}$, and $3 h$ after training in a passive avoidance task. Subgroups were retested at $24 \mathrm{~h}$, $48 h, 72 h, 1$ week, and 4 weeks. $A$ temporal gradient of retrograde amnesia was produced, with ECS still being effective even when given $3 h$ after training. The gradient was maintained over all retest times. No evidence of recovery could be detected.

In clinical studies of patients following head trauma, it has been frequently observed that the period of time for which there has been retrograde amnesia progressively shrinks, leaving usually only a brief period for which there is a permanent retrograde amnesia (Russell \& Nathan, 1946). There has recently been considerable controversy concerning the permanence of the retrograde amnesia produced by electroconvulsive shock (ECS) in animals. Some studies (Zinkin \& Miller, 1967; Kohlenberg \& Trabasso, 1968; Miller, 1968) have shown recovery, whereas others (Chevalier, 1965; Herz \& Peeke, 1967; Luttges \& McGaugh, 1967; Geller \& Jarvik, 1968) have found the amnesia to be permanent over several weeks. All of these studies, except one, have used training-ECS intervals which have been brief (seconds) and have achieved apparently complete amnesia at the earliest testing time. Miller (1968), however, used four training-ECS intervals (3.1 to $3,000 \mathrm{sec}$ ) and retested his Ss at $24 \mathrm{~h}$ and again at $48 \mathrm{~h}$. He obtained recovery from the amnesia produced with the three longer training-ECS treatment intervals, but obtained no recovery from that produced with the shortest training-ECS interval. If the period of retrograde amnesia following ECS shrinks to an irreducible minimum on analogy with the retrograde amnesia produced by head trauma, this has implications both for consolidation theory and for theories concerning the mechanism of action of ECS.

In our laboratory, we have obtained gradients of retrograde amnesia of up to $23 \mathrm{~h}$ (Robustelli et al, in press). The discrepancy between these long gradients and the extremely brief ones of a few seconds obtained by some other authors (Chorover \& Schiller, 1966) has been somewhat puzzling. Chorover \& Schiller (1966) proposed that the true gradient of retrograde amnesia is brief and that the impairment obtained at longer time intervals is due to effects of ECS on processes unrelated to memory consolidation.

The purpose of the present investigation was to examine the possibility of spontaneous recovery from the partial amnesias produced at training-ECS intervals of greater than $10 \mathrm{sec}$ in our experimental situation.

\section{EXPERIMENT 1 Subjects}

The Ss were 240 female CF 1 albino mice approximately 6 weeks old, housed eight to a cage with ad lib access to food and water.

\section{Apparatus}

Animals were trained in a step-through apparatus consisting of a trough-shaped two-compartment box (Jarvik \& Kopp, 1967). In the smaller transparent compartment, Ss were exposed to a bright Tensor lamp. The smaller compartment was connected to the larger dark compartment by an opening $3.2 \mathrm{~cm}$ high, $2.7 \mathrm{~cm}$ wide, and flush with the floor. The floors of both compartments consisted of a pair of parallel metal plates. The opening between the compartments could be closed by a guillotine door.

\section{Procedure}

The Ss were placed into the smaller lit compartment facing away from the door, and they stepped spontaneously into the larger dark compartment. A timer was started manually when the $S$ s were placed in the apparatus and was stopped automatically when the Ss crossed a photocell on the wall of the larger compartment, $8 \mathrm{~cm}$ from the opening. When the timer stopped, the guillotine door was closed, and the Ss remained in the dark compartment without shock for $30 \mathrm{sec}$. At the end of this period, a 350-microampere foot shock was delivered, the guillotine door was opened, and the Ss were permitted to escape to the lit compartment from which they were removed. On the retest trials, Ss were placed in the lit compartment, and their latency to step to the dark compartment was recorded. Those Ss remaining longer than $600 \mathrm{sec}$ were removed.

Electroconvulsive shock (15 milliamperes for $0.2 \mathrm{sec}$ ) was administered transcorneally, outside the conditioning apparatus, using a Hans 2-C electroshock apparatus.

The Ss were divided into four main groups, one control group, in which Ss were returned to their home cages immediately after training, and three experimental groups receiving ECS $10 \mathrm{sec}$, $120 \mathrm{sec}$, and $3 \mathrm{~h}$ after training. The Ss receiving ECS $120 \mathrm{sec}$ and $3 \mathrm{~h}$ after training spent the training-ECS interval in their home cages. Each main group was divided into four subgroups of $15 \mathrm{Ss}$ according to the time at which they were to be retested. Retest was $24 \mathrm{~h}, 48 \mathrm{~h}, 72 \mathrm{~h}$, or 1 week after training.

\section{RESULTS}

Overall analysis of variance (Kruskal-Wallis) revealed no significant differences in training-trial latencies among the 16 subgroups. Analyses of variance performed across the main groups were significant for each time of retest at $p<0.001$, indicating that the ECS treatment was sufficient to differentiate the groups at all retest times. A Wilcoxon rank sum test (Wilcoxon \& Wilcox, 1964) was performed between training and retest latencies for each subgroup. Retest latencies were significantly higher ( $p<0.001)$ than training latencies for all the subgroups of both the control (no-ECS) and the 3-h ECS groups. The retest latencies for all the subgroups of the 120-sec ECS group did not differ significantly from their training latencies. However, the retest latencies of the subgroups given ECS at $10 \mathrm{sec}$ and retested at $24 \mathrm{~h}$ and $48 \mathrm{~h}$ were different from their training latencies $(p<0.01$ and $p<0.025$, respectively), but were lower on the retest than on the training trial. At the $72 \mathrm{~h}$ and 1 week retest, the latencies of the 10 -sec ECS subgroups were not significantly different from their training latencies. All ECS-treated subgroups had lower latencies than controls (no ECS) at all retest intervals. Significant differences from controls (Wilcoxon multiple comparison, Wilcoxon \& Wilcox, 1964) were found for each subgroup except the 3-h ECS, retested at $24 \mathrm{~h}, 48 \mathrm{~h}$, and $72 \mathrm{~h}$. At the 1-week retest, the latencies of the $3 \cdot \mathrm{h}$ ECS were, however, significantly less $(p<0.01)$ than controls. A Kruskal-Wallis analysis of variance across retest times for each ECS condition revealed no differences related to time of retest.

The results of the first experiment failed to show any suggestion of recovery from 


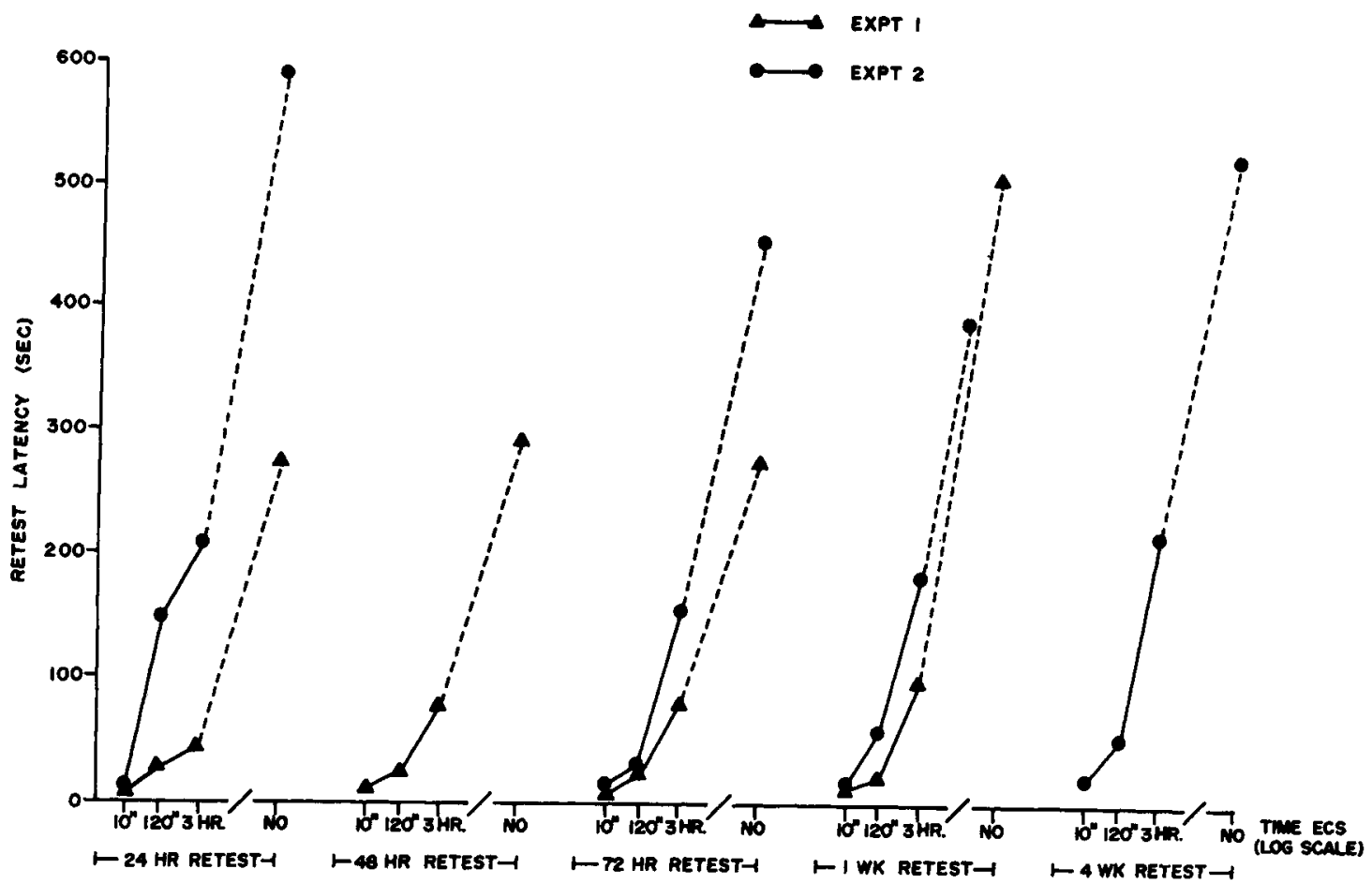

Fig. 1. Median retest latencies for Ss of Experiments 1 and 2 .

the amnesic effects of ECS given $10 \mathrm{sec}$, $120 \mathrm{sec}$, or $3 \mathrm{~h}$ after training over a 1-week period. However, a proactive effect of ECS is demonstrated by latencies lower on the retest than on the training trial for the 10-sec ECS subgroups retested at $24 \mathrm{~h}$ and $48 \mathrm{~h}$. The latencies of the 10-sec ECS subgroups, though they rose at the $72-\mathrm{h}$ and 1-week retest times, did not differ significantly from the training latencies. That is, a proactive effect upon step-through latencies appeared to have dissipated, but the amnesia remained complete. It is possible that the time intervals used in the first experiment, even though longer than those commonly employed, were still too short to permit demonstration of recovery.

\section{EXPERIMENT 2}

A second experiment was conducted exactly as the first, except that a 4-week retest was substituted for the 48 -h retest. In this experiment, 288 mice were used to give an $\mathrm{N}$ of 18 per subgroup.

As can be seen in Fig. 1, the results of this experiment essentially replicate and extend those of the first. A Kruskal-Wallis analysis of variance showed no significant effect of time of retest for any of the four main groups $(p>0.5,0.7,0.8,0.8$ for the control, ECS $3 \mathrm{~h}$, ECS $120 \mathrm{sec}$, and ECS $10 \mathrm{sec}$, respectively). All ECS-treated subgroups, including those given ECS $3 \mathrm{~h}$ after training, had latencies significantly lower than controls at all times of retest in this experiment.

\section{DISCUSSION}

The results of the present study show no spontaneous recovery over a 4-week period from the amnesia produced by ECS, either when the amnesia is complete or when it is only partial. This is not what would be predicted on the basis of an analogy with the retrograde amnesia produced by head trauma, where there is spontaneous shrinkage with time, nor does it agree with the results of Miller (1968), who found recovery at the longer training-ECS intervals.

Caution, however, should be exercised when interpreting the various results of experiments testing the permanence of the amnesia produced by ECS, both with regard to the specific experimental design being used and in terms of the implications of the findings for consolidation theory.

Previous results from our laboratory have demonstrated a clear-cut proactive effect of ECS on the step-through latencies of trained mice (Robustelli et al, 1969) and naive mice (Aron et al, 1969) lasting for $24 \mathrm{~h}$. In the present investigation, a proactive effect can be demonstrated up to $48 \mathrm{~h}$, but not thereafter. All of the studies that have shown recovery from the amnesia produced by ECS have used ECS-retest intervals of no longer than $72 \mathrm{~h}$ (Cooper \& Koppenaal, 1964; Zinkin \& Miller, 1967; Kohlenberg \& Trabasso, 1968; Miller, 1968). Since it is known that the extent of the amnesia produced by ECS is dependent upon ECS parameters, task, and species variables, it might be suggested that in the above studies ECS had little, if any, true retrograde effect and that what was being demonstrated was a recovery from the proactive rather than the retroactive effects of ECS.

Independently of these technical considerations, however, the finding of recovery from the amnesic effects of $E \dot{C} S$ would not invalidate consolidation theory, nor do the results of the present investigation necessarily support it. A distinction has to be made between the consolidation hypothesis itself and hypotheses concerning the mechanism of action of ECS. Electroconvulsive shock is most generally assumed to destroy a labile memory trace and thus arrest the formation of a stable memory trace at the time of its delivery. This would require that the resultant amnesia be permanent, since the labile trace is physically destroyed by the treatment. However, the gradient produced by ECS might be maintained over long testing intervals but be unrelated to consolidation, for example, a potentiation of ECS by the preceding foot shock which diminishes as the foot shock-ECS interval increases. On the other hand, it might be suggested that the convulsion and/or the subsequent postical. state temporarily interrupts a consolidation process which might then be reinstated after the passage of time. Such a reinstatement might possibly occur at time intervals longer than $24 \mathrm{~h}$. Under these 
circumstances, a permanent amnesia would be produced only if the interruption covered the entire consolidation time.

\section{REFERENCES}

ARON, C., GLICK, S. D., \& JARVIK, M. E. Long lasting proactive effects of a single ECS. Physiology \& Behavior, 1969, 4, 785-790.

CHEVALIER, J. A. Permanence of amnesia after a single post trial electroconvulsive seizure. Joumal of Comparative \& Physiological Psychology, 1965, 59, 125-127.

CHOROVER, S. L., \& SCHILLER, P. H. $R$ e-examination of prolonged retrograde amnesia in one trial learning. Journal of Comparative \& Physiological Psychology, $1966,61,34-41$.

COOPER, R. N., \& KOPPENAAL, R. J. Suppression and recovery of a one trial avoidance response after a single ECS. Psychonomic Science, 1964, 1, 303-304.

GELLER, A., \& JARVIK, M. E. Electroconvulsive shock induced amnesia and recovery. Psychonomic Science, 1968, 10, 15-16.

HERZ, M. J., \& PEEKE, H. V. S. Permanence of retrograde amnesia produced by electroconvulsive shock. Science, 1967, 156, 1396-1397.

JAR VIK, M. E., \& KOPP, R. An improved one trial passive avoidance learning situation. Psychological Reports, 1967, 21, 221-224.

KOHLENBERG, R., \& TRABASSO, T. Recovery of a conditioned emotional response after one or two electroconvulsive shocks. Journal of Comparative \& Physiological Psychology, $1968,65,270-273$.

LUTTGES, M. W., \& McGAUGH, J. L.
Permanence of retrograde amnesia produced by electroconvulsive shock. Science, 1967, $156,408-410$.

MILLER, A. J. Variations in retrograde amnesia with parameters of electroconvulsive shock and time of testing. Journal of Comparative \& Physiological Psychology, 1968, 66, 40-47.

ROBUSTELLI, F., GELLER, A., ARON, C., \&

JARVIK, M. E. The relationship between the amnesic effect of electroconvulsive shock and strength of conditioning in a passive avoidance task. Communications in Behavioral Biology, 1969, 3, 233-239.

ROBUSTELLI, F., GELLER, A., \& JARVIK, M. E. Temporal gradient of 23 hours with electroconvulsive shock and its implications. Communications in Behavioral Biology, in press.

RUSSELL, W. R., \& NATHAN, P. W. Traumatic amnesia. Brain, 1946, 69, 280-300.

WILCOXON, F., \& WILCOX, R. A. Some rapid approximate statistical procedures. Pearl River, N.Y: Lederle Laboratories Division, American Cyanamid Co., 1964.

ZINKIN, S., \& MILLER, A. J. Recovery of memory after amnesia induced by ECS. Science, 1967, 155, 102-104.

NOTE

1. This research was supported by a USPHS grant MH 05319, and a Special Fellowship from the National Institute of Neurological Diseases and Stroke, 1F10 NS0223201. The authors wish to thank Mr. David Barth for his technical assistance.

\section{EXPERIMENT 1}

The Ss were divided into two groups of 12 animals each. Group C (control) was given training and retest trials without any additional treatment. Group S.E (sham-ether) was treated as Group C but was sham operated under ether anesthesia $1 \mathrm{~h}$ after the training trial. The sham-ether operation had five steps: (1) placing a mouse in a beaker containing volatile ethyl ether at $25^{\circ} \mathrm{C}$ for approximately $45 \mathrm{sec}$ until surgical anesthesia was obtained, (2) shaving the dorsal side of the mouse's head, (3) placing the mouse in the ether jar for a second time until surgical anesthesia was again obtained, (4) making an 8-mm skin incision along the midline of the head with a scalpel, and (5) closing the wound with a $7-\mathrm{mm}$ wound clip. For one-third of the mice, a third dose of ether was necessary between the fourth and fifth steps.

Results

As shown in Table 1, Ss receiving the S-E treatment $1 \mathrm{~h}$ after training had lower retest latencies than untreated C Ss. This difference was significant at $p<.01$ (Wilcoxon \& Wilcox, 1964). EXPERIMENT 2

The importance of the ether and of the skin incision in producing the sham-ether effect were separately evaluated. The Ss were divided into four groups of 12-14 animals each. Groups $\mathrm{C}$ and S-E were given the same control and sham-ether treatments, respectively, as the $S s$ in Experiment 1. Group S-NE (sham-no ether) was treated the same way as Group S-E except that no ether or other anesthesia was used. These Ss were held by the neck and tail while they were shaved and given a skin incision and a wound clip.

S. D. GLICK, R. K. NAKAMURA, and M. E. JARVIK, Albert Einstein College of Medicine, Yeshiva University, Bronx, N.Y. 10461

Mice were given a sham operation (skin incision plus wound clip) under ether, a sham operation without ether, or ether alone after training in a passive-avoidance task and were tested for retention $24 \mathrm{~h}$ later. When administered $1 \mathrm{~h}$ after training, sham-ether and sham treatments, but not ether treatments, induced amnesia. Amnesia due to the sham-ether treatment was greater than that due to the sham-no ether treatment. When given $6 \mathrm{~h}$ after training, only the sham-ether treatment induced significant amnesia.

This report was generated by an attempt to produce retrograde amnesia in mice by brain damage. Our initial aim was diverted, however, by the discovery that a sham operation without brain damage was sufficient to produce amnesia. Group E (ether) was treated in the same Consequently, attention was shifted to an way as Group S-E except that no sham analysis of this latter phenomenon. SUBJECTS

The Ss were female CF1 mice, 6 to 8 weeks old, housed 8.10 to a cage.

APPARATUS AND PROCEDURE

The conditioning apparatus was identical to that described by Jarvik \& Kopp (1967) Briefly, the trough-shaped step-through apparatus consisted of a two-compartment box in which the Ss could receive a 350 microA foot shock when stepping from the small lighted compartment to the larger dark one. The conditioning trial was terminated when Ss escaped back to the light compartment from which they were removed. All retest trials were conducted with the same procedure and always occurred $24 \mathrm{~h}$ following the conditioning trial. All latencies with which Ss entered the large dark compartment on both conditioning and retest trials were recorded. operation was performed. These Ss were surgically anesthetized in ether with the same frequency as were the $S s$ in Group S-E, i.e., one-third of the Ss in Group E were placed in the ether jar three times and the rest only twice.
Results

As shown in Table 2, the S-E effect was replicated. The Ss receiving the S-E treatment $1 \mathrm{~h}$ after training again had significantly $(p<.01)$ lower retest latencies than C Ss. The Ss receiving the S-NE treatment also had significantly $(p<.05)$ lower retest latencies than the C Ss. However, amnesia due to the S-E treatment was significantly $(p<.05)$ greater than that due to the S-NE treatment. The Ss receiving the $\mathrm{E}$ treatment showed no amnesia whatsoever and had significantly $(p<.01)$ higher latencies than Ss receiving either the S-E or the S-NE treatment. 